\title{
Genetic deletion of genes in the cerebellar rhombic lip lineage can stimulate compensation through adaptive reprogramming of ventricular zone-derived progenitors
}

Alexandre Wojcinski ${ }^{1}$, Morgane Morabito ${ }^{1}$, Andrew K. Lawton ${ }^{1}$, Daniel N. Stephen ${ }^{1}$ and Alexandra L. Joyner ${ }^{1,2^{*}}$ (D)

\begin{abstract}
Background: The cerebellum is a foliated posterior brain structure involved in coordination of motor movements and cognition. The cerebellum undergoes rapid growth postnataly due to Sonic Hedgehog (SHH) signalingdependent proliferation of ATOH1 + granule cell precursors (GCPs) in the external granule cell layer (EGL), a key step for generating cerebellar foliation and the correct number of granule cells. Due to its late development, the cerebellum is particularly vulnerable to injury from preterm birth and stress around birth. We recently uncovered an intrinsic capacity of the developing cerebellum to replenish ablated GCPs via adaptive reprogramming of Nestinexpressing progenitors (NEPs). However, whether this compensation mechanism occurs in mouse mutants affecting the developing cerebellum and could lead to mis-interpretation of phenotypes was not known.

Methods: We used two different approaches to remove the main SHH signaling activator GLI2 in GCPs: 1) Our mosaic mutant analysis with spatial and temporal control of recombination (MASTR) technique to delete Gli2 in a small subset of GCPs; 2) An Atoh1-Cre transgene to delete Gli2 in most of the EGL. Genetic Inducible Fate Mapping (GIFM) and live imaging were used to analyze the behavior of NEPs after Gli2 deletion.

Results: Mosaic analysis demonstrated that SHH-GLI2 signaling is critical for generating the correct pool of granule cells by maintaining GCPs in an undifferentiated proliferative state and promoting their survival. Despite this, inactivation of GLI2 in a large proportion of GCPs in the embryo did not lead to the expected dramatic reduction in the size of the adult cerebellum. GIFM uncovered that NEPs do indeed replenish GCPs in Gli2 conditional mutants, and then expand and partially restore the production of granule cells. Furthermore, the SHH signaling-dependent NEP compensation requires Gli2, demonstrating that the activator side of the pathway is involved.

Conclusion: We demonstrate that a mouse conditional mutation that results in loss of SHH signaling in GCPs is not sufficient to induce long term severe cerebellum hypoplasia. The ability of the neonatal cerebellum to regenerate after loss of cells via a response by NEPs must therefore be considered when interpreting the phenotypes of Atoh 1Cre conditional mutants affecting GCPs.
\end{abstract}

Keywords: Cerebellum, SHH signaling, GLI2, Nestin-expressing progenitors, Neurogenesis, Atoh1-Cre, Regeneration

\footnotetext{
* Correspondence: joynera@mskcc.org

'Developmental Biology Program, Sloan Kettering Institute, 1275 York

Avenue, Box 511, New York, NY 10065, USA

Biochemistry, Cell and Molecular Biology Program, Weill Cornell Graduate

School of Medical Sciences, New York, NY 10065, USA
}

(c) The Author(s). 2019 Open Access This article is distributed under the terms of the Creative Commons Attribution 4.0 International License (http://creativecommons.org/licenses/by/4.0/), which permits unrestricted use, distribution, and

reproduction in any medium, provided you give appropriate credit to the original author(s) and the source, provide a link to the Creative Commons license, and indicate if changes were made. The Creative Commons Public Domain Dedication waiver (http://creativecommons.org/publicdomain/zero/1.0/) applies to the data made available in this article, unless otherwise stated. 


\section{Background}

The cerebellum (CB) consists of $80 \%$ of the neurons in the human brain [1] (60\% in mouse [2]), and is involved in balance and motor coordination, but also modulates language, reasoning and social processes via its connections throughout the forebrain [3-7]. The CB undergoes its major growth in the third trimester and infant stage in humans, and the first 2 weeks after birth in mice, primarily due to expansion of the granule cell precursor $(\mathrm{GCP})$ pool in the external granule cell layer (EGL) [8-10]. Given the late development of the $\mathrm{CB}$ compared to other brain regions, the $\mathrm{CB}$ is particularly sensitive to environmental and clinical factors that impact on growth (or cause injury) around birth. Furthermore, CB hypoplasia and prenatal injury is the second leading factor associated with autism [11]. It is therefore important to identify genes that regulate cerebellum development. Many of the genes have been identified based on motor defects in homozygous null mutant mice, or in conditional mutants that remove genes in specific cell lineages. Intrinsic growth compensation mechanisms involving lineages where the gene does not function could however, obscure the normal function of a gene in cerebellar growth.

The CB develops from two germinal zones. The ventricular zone (VZ) gives rise to all the inhibitory neurons, including Purkinje cells (PCs) [12] as well as Nestin-expressing progenitors (NEPs) that expand in the cerebellar cortex after birth to produce astrocytes, including specialized Bergmann glia, and late born interneurons of the molecular layer $[13,14]$. Ptf $1 a^{C r e}$ mice have been used to delete genes in inhibitory neurons and some glia [15]. Excitatory neurons including granule cells (GCs) originate from the upper rhombic lip [16-18]. In mice, the EGL is established between embryonic day (E) 13.5 and E15.5. Atoh1-expressing GCPs then proliferate and expand in the EGL until postnatal day $(\mathrm{P}) 15$ in response to Sonic Hedgehog (SHH) secreted by PCs [19-21]. When GCPs become postmitotic, they migrate down Bergmann glial fibers to form the internal granule cell layer (IGL). Interestingly, in rodent models the developing $\mathrm{CB}$ has been found to have a remarkable ability to recover from some injuries [22-24]. Indeed, we recently found that proliferating cerebellar GCPs can be replaced via adaptive reprogramming of NEPs after an acute depletion of the perinatal EGL due to irradiation [25-27]. Thus, NEPs in the neonatal $\mathrm{CB}$ have highly plastic behaviors. However, whether NEPs are harnessed to replenish cells lost in developmental mutants that lack key factors required for expansion and survival of GCPs has not been addressed.

One of the major pathways driving $\mathrm{CB}$ development is $\mathrm{HH}$ signaling. There are three hedgehog $(H h)$ genes in mammals, Indian (Ihh), Desert (Dhh) and Shh [28, 29]. $S h h$, the most widely expressed $H h$ gene, is required for development of most organs [29] by regulating a variety of cell behaviors including cell death, proliferation, specification and axon guidance. The cellular context (i.e. tissue, developmental stage, convergence of other signaling pathways) and concentration of $\mathrm{SHH}$ are thought to determine the particular response of a cell to $\mathrm{SHH}$. $\mathrm{HH}$ signal transduction is mediated by the receptors Patched1 (PTCH1) and Smoothened (SMO) [28-30]. In the absence of $\mathrm{HH}$ signaling, PTCH1 constitutively represses SMO activity, whereas $\mathrm{HH}$ binding relieves this inhibition, in part by allowing accumulation of SMO in cilia [31]. The GLI/Ci transcription factors are the effectors of the HH pathway. In mammals, the transcriptional activator (A) and repressor (R) functions of the GLIs have been divided between the three proteins [32]. A general rule is that high levels of $\mathrm{HH}$ signaling induce the formation of a GLI2 activator (GLI2 ${ }^{\mathrm{A}}$ ) and this leads to transcription and translation of an addition activator, GLI1 $^{\mathrm{A}}$, while a reduction or absence of the ligand allows for the formation of a GLI3 repressor $\left(\right.$ GLI3 $\left.{ }^{R}\right)$. Importantly, we demonstrated that Gli1 expression is dependent on GLI2 $/ 3^{\mathrm{A}}$, and thus is only expressed in cells receiving a high level of $\mathrm{HH}$ signaling [33, 34]. The three Gli genes, Shh, Smo, Ptch1 and Ptch2 are expressed in the $\mathrm{CB}$ and all but Ptch2 are required for CB development [20, 21, 35-37]. In particular, we have shown that $\mathrm{SHH}$ functions by inducing $\mathrm{GLI} 1^{\mathrm{A}} / 2^{\mathrm{A}}$ and is required for expansion of GCPs, primarily after birth $[20,38]$, whereas Gli3 is not required in the cerebellum after E12.5 [36]. In addition to the crucial role of SHH in generating the pool of GCs, expansion of NEPs and thus production of NEP-derived interneurons and astroglia (astrocytes and Bergmann glia) also require SHH-signaling [13, 25, 39]. Furthermore, HH-signaling in NEPs is crucial for expansion of NEPs, recovery of the EGL and scaling of interneuron numbers after injury to the EGL [25].

Here we report that deletion of Gli2 in the vast majority of the GCPs is not sufficient to induce major cerebellar hypoplasia. Using our MASTR technique [40] in a mosaic mutant analysis of the effect of deleting Gli2 in scattered GCPs, we found that HH/GLI2-signaling is indeed necessary to maintain GCPs in an undifferentiated and proliferative state and to promote their survival. However, and similar to when the EGL is depleted using irradiation, we uncovered that NEPs are harnessed to repopulate the EGL and then wild type progenitors differentiate into GCs when Gli2 is deleted in most GCPs using an Atoh1-driven constitutive Cre [41]. Our results not only provide more evidence for the unusual ability of the $\mathrm{CB}$ to recover from perinatal stress, but also reveal that NEP-dependent compensation should be taken into account when studying genes implicated in GCP development or survival and when using the Atoh1-Cre transgene. 


\section{Methods}

\section{Animals}

The following mouse lines were used: Gli2 $2^{\text {flox/flox }}$ [20], Atoh1-Cre [41], Atoh-FlpoER, Nestin-FlpoER (a transgene similar to that described in [40]) and Rosa26MASTR(frt-STOP-frt-GFPcre) [40], Atoh1-GFP [42], Nes-CFP [43], Rosa26 FRT-STOP-FRT-TDTom (Jackson Laboratory, 021875). The Atoh-FlpoER line, was made using the FLPoER1 cDNA described in [40] by subcloning it into the Atoh1 expression construct described in [17]. All mouse lines were maintained on an outbred Swiss Webster background and both sexes were used for the analysis. Animals were housed on a $12 \mathrm{~h}$ light/dark cycle and were given access to food and water ad libitum. All experiments were performed using mice ages P0-P30.

Tamoxifen (Tm, Sigma-Aldrich) was dissolved in corn oil (Sigma-Aldrich) at $20 \mathrm{mg} / \mathrm{ml}$. P2 Atoh1-FlpoER/+; R26 $6^{\text {MASTR/+}} ;$ Gli2 flox/flox, Atoh1-FlpoER/+; R26 $6^{\text {MASTR/+; }}$ Gli2 $2^{\text {flox/flox }}$ and P0 Nes-FlpoER/+; R26 FSF-TDTom $/+$, NesFlpoER/+; R26 $6^{\text {FSF-TDTom/+ }}$ Atoh-GFP/+ mice as well as Nestin-FlpoER/+; R26 ${ }^{\text {MASTR/+}}$; Gli2 flox/flox , Atoh1-Cre/+; Gli2 $2^{\text {flox/flox }}$ and Nestin-FlpoER; R2 $6^{\text {MASTR/+ }}$; Atoh1-Cre/+; Gli2 $2^{\text {flox/flox }}$ mice and littermate controls received one $200 \mu \mathrm{g} / \mathrm{g}$ dose of Tm via subcutaneous injection. $50 \mu \mathrm{g} / \mathrm{g}$ 5-ethynyl-2_-deoxyuridine (EdU; Invitrogen) was administered via intraperitoneal injection $(10 \mathrm{mg} / \mathrm{ml}$ in sterile saline) one hour before the animals were sacrificed.

\section{Tissue processing, immunohistochemistry (IHC) and transcript detection}

For animals younger than $\mathrm{P} 4$, they were anaesthetized by cooling and brains were dissected out and fixed in $4 \%$ paraformaldehyde overnight at $4{ }^{\circ} \mathrm{C}$. Animals P4-30 received $50 \mu \mathrm{l}$ intraperitoneal injections of ketamine and received ice-cold PBS via transcardial perfusion followed by $4 \%$ paraformaldehyde. Brains were collected and submersion fixed in $4 \%$ paraformaldehyde overnight at $4{ }^{\circ} \mathrm{C}$. Tissues were processed for frozen embedding in optimal cutting temperature (OCT) compound and sectioned in the parasagittal plane on a Leica cryostat at $12 \mu \mathrm{m}$. For IHC, sections were incubated overnight at $4{ }^{\circ} \mathrm{C}$ with the following primary antibodies: rabbit anti-Ki67 (Thermo Scientific, RM-9106-S0), mouse anti-P27 (BD Pharmigen, 610,241), rabbit anti-PAX6 (Millipore, AB2237), goat anti-GLI2 (R\&D System, AF3635), Goat anti-SOX2 (R\&D System, AF2018), rabbit anti-GFP (Life Technologies, A11122), rat anti-GFP (Nacalai Tesque, 04404-84), mouse anti-NeuN (Millipore, MAB377) diluted in PBS with 5\% BSA (Sigma-Aldrich) and $0.3 \%$ Triton X-100 (Fisher Scientific). Sections were then exposed for $2 \mathrm{~h}$ at room temperature to secondary species-specific antibodies conjugated with the appropriate Alexa Fluor (1:500; Invitrogen). EdU was detected using a commercial kit (Life Technologies) after the IHC reactions.
TUNEL staining and in situ hybridization were performed according to standard protocols. Cre and Gli1 cDNAs were used as the template for synthesizing digoxygenin-labeled riboprobes. Images were collected on a DM6000 Leica microscope and processed using Photoshop software.

\section{Live imaging}

Ex vivo cerebellar slice culture was done as previously described [25]. Briefly, P8 cerebella were embedded in $2.5 \%$ low-melting point agarose and saggitally sliced at $250 \mu \mathrm{M}$ on a Vibratome. Slices were immediately taken to either a Leica TCS SP8 or SP5 confocal microscope platform. Slices were maintained in Eagle's Basal Medium with $2 \mathrm{mM}$ L-glutamine, $0.5 \%$ glucose, $50 \mathrm{U} / \mathrm{ml}$ Penicillin-streptomycin, $1 \times 327$ and $1 \times 1$ N2 supplements at $37^{\circ} \mathrm{C}$ and $5 \% \mathrm{CO}_{2}$. Image stacks were acquired every 5 min for $\sim 4 \mathrm{~h}$. Cell tracking was performed using Imaris software. The autoregressive tracking function was employed with a spot size of $6 \mu \mathrm{M}$ and a step size of $7 \mu \mathrm{M}$. Manual correction was performed.

\section{Quantifications and statistical analyses}

ImageJ software was used to measure the area $\left(\mathrm{mm}^{2}\right)$ of cerebellar sections near the midline. For all IHC staining, cell counts were obtained using ImageJ and Neurolucida Software. For each developmental stage, three sections were analyzed per animal and $\geq 3$ animals. Statistical analyses were performed using Prism software (GraphPad) and significance was determined at $P<0.05$. All statistical analyses were two-tailed. For two-group comparisons with equal variance as determined by the $F$-test, an unpaired Student's $t$ test was used. Welch's correction was used for unpaired $t$-tests of normally distributed data with unequal variance. $P$ values are indicated in the figures. No statistical methods were used to predetermine the sample size, but our sample sizes are similar to those generally employed in the field. No randomization was used. Data collection and analysis were not performed blind to the conditions of the experiments.

\section{Results}

Mosaic analysis reveals SHH-GLI2 signaling is critical for maintaining GCPs in an undifferentiated proliferative state and promoting their survival

Our previous studies demonstrated that loss of the majority of $\mathrm{HH}$-signaling in the entire $\mathrm{CB}$ at mid-gestation (Nes-Gli2 conditional knockout or CKO - Nestin-Cre; Gli2 $2^{\text {flox/flox }}$ mice) results in an almost complete lack of GCPs at birth and a very diminished CB in adults [20]. Since HH-signaling is required after birth in NEPs for their expansion and production of late born interneurons and astrocytes in the $\mathrm{CB}$ [13], it is possible that part 
of the phenotype observed in Nes-Gli2 CKOs was due to loss of HH-signaling in Non-GCP cells. We therefore took two approaches to test the cell autonomous requirement for $\mathrm{HH}$ signaling in GCPs. First we used the $R 26^{\text {FSF-GFPcre }}$ MASTR allele $\left(R 26^{\text {MASTR }}\right)$ [40] and a Atoh1-FlpoER transgene to knock out Gli2 in scattered GCPs at $\sim$ P3 by administering Tamoxifen (Tm) at P2 and analyzed the percentage of undifferentiated GFP+ GCPs (GFP+ cells in the proliferating outer EGL/total GFP + cells - proliferating and post mitotic) at both P4 and P8 (Fig. 1a-c). We did indeed observe a significant decrease in the percentage of GFP+ cells that were GCPs in the medial CB (vermis) of P8 Atoh1-M-Gli2 CKOs $\left(R 26^{\text {MASTR/+}}\right.$; Atoh1-FlpoER/+; Gli2 $2^{\text {flox/flox }}$ mice; $\left.n=3 ;\right)$ compared to Atoh1-M-Gli2 heterozgous (het) controls $\left(R 26^{\text {MASTR/+}} ;\right.$ Atoh1-FlpoER/+; Gli2 $2^{\text {flox/+ }}$ mice; $\left.n=3\right)$ (29.79\% compared to $67.09 \%$ ) (Fig. 1d). Using a $1 \mathrm{~h}$ pulse of EdU, we found that the proliferation index (\#EdU+ GFP+ cells in the outer EGL/total GFP+ cells in the outer EGL) of Atoh1-M-Gli2 CKO GCPs was significantly decreased compared to controls $(n=3 ; 14.39 \%$ compared to $29.06 \%$ ) (Fig. 1e). At P4, there was no significant difference in the percentage of undifferentiated GFP+ GCPs between Atoh1-M-Gli2 CKOs and controls $(p=0.162)$ (Fig. 1d). However, we observed a significant decrease in the proliferation index in P4 Atoh1-M-Gli2 CKO cerebella (CKO vs control, $p=0.015$ ) (Fig. 1e). At $\mathrm{P} 4$, only 2 days after Tm injection, the number of GFP+ cells in the oEGL was not significantly reduced (CKO vs control, $p=0.081$ ) (Additional file 1: Figure S1a). Nevertheless, TUNEL staining revealed a significant increase in cell death in the entire EGL at P4 $(69.44 \pm 7.76 / \mathrm{sec}-$ tion in mutants vs $37.67 \pm 5.1$ in controls, $p=0.027$ ). We performed the same analysis in the lateral $\mathrm{CB}$ (hemispheres) and found a similar outcome (Additional file 1: Figure S1b-d). These results reveal that $\mathrm{HH}$-signaling through GLI2 plays an important role in maintaining GCPs in an undifferentiated state, and also promotes their proliferation and survival.

As an alternative approach to a mosaic mutant analysis, we deleted Gli2 in the vast majority of GCPs (Atoh1-Cre/+; Gli2 $2^{\text {flox/flox }}$ or Atoh1-Gli2 CKOs). Consistent with previous studies using whole cerebellum $\mathrm{Cre}$ transgenes and our mosaic analysis, at P0 the anterior vermis of Atoh1-Gli2 CKOs $(n=5)$ appeared consistently smaller than controls $\left(G l i 2^{f l o x} f f l o x\right)$ and the EGL was greatly diminished (Fig. 1g-j). SHH-GLI2 signaling loss was confirmed by the lack of Gli1 expression in the EGL of Atoh1-Gli2 CKO cerebella (Fig. 1g-h). Moreover, proliferation (Ki67) in the outer EGL and differentiation (P27 marking post mitotic cells in the inner EGL) were disrupted in the mutant EGL since two distinct EGL layers were not present (Fig. 1i-j). Interestingly, we observed an apparent increase of Gli1 expression in the Purkinje cell layer (PCL) suggesting that deletion of Gli2 in the EGL induced a cell nonautonomous up-regulation of $\mathrm{HH}$-signaling in this layer (star in Fig. 1g-h). The lack of a phenotype in the posterior vermis is likely explained by low expression of Cre [44] in this region and thus low recombination [45] (Additional file 2: Figure S2).

All together, these results confirm a major role played by SHH-signaling through GLI2 to promote the expansion of the EGL and thus ensure the generation of the correct number of GCs.

\section{The size of the Atoh1-Gli2 CKO cerebellum progressively recovers after birth}

We have recently shown that the size of the $\mathrm{CB}$ can recover to $\sim 80 \%$ its normal size after postnatal injury (irradiation) to the EGL [25]. To test whether genetic ablation of Gli2 in the EGL can trigger a similar recovery mechanism, we analyzed the phenotype of adult (P30) Atoh1-Gli2 CKO cerebella. The area of mid-sagittal sections of P30 animals was quantified, and revealed only a $21.7 \pm 12.0 \%$ reduction $(n=$ 6) in Atoh-Gli2 CKOs compared to littermate controls (Fig. 2a-d). Unlike normal mice, we observed a large variability in the area of the midline cerebellum and degree to which the IGL was depleted in mutants, indicating some mutant cerebella recovered the EGL better than others (compare Fig. $2 \mathrm{~b}$ and $\mathrm{c}$ ). We then measured the area of midsagittal cerebellar sections from P4, P8 and P12 mice to determine the growth trajectory of mutant mice compared to controls (Fig. 2e-j). The size of Atoh1-Gli2 CKOs cerebella was significantly reduced by $\sim 20 \%$ at all time points (Fig. 2k-1). Since our mosaic mutant results showed a similar behavior of Gli2 CKO GCPs in the hemispheres and vermis, we analyzed the phenotype of Atoh1-Gli2 CKOs in the hemisphere. Curiously, unlike the vermis we did not observe a significant decrease in the size of the mutant hemispheres at P30 compared to controls ( $p=0.152)$ (Fig. 3a-c). Analysis of hemispheric sagittal sections from P4 $(n=3)$, P8 $(n=3)$ and P12 $(n=3)$ revealed how the cytoarchitecture recovered (Fig. 3d-i). Interestingly, whereas the vermis of Atoh1-Gli2 CKOs mice at P8 showed a clear hypoplasia phenotype, the hemispheres exhibited extra folia (arrow in Fig. 3g), suggesting different compensation responses in the two locations of the CB in Atoh1-Gli2 CKOs.

In summary, we found that depletion of the EGL at P0 by removing Gli2 from embryonic GCPs is not sufficient to induce consistent major hypoplasia of the vermis at P30. This raised the possibility of a compensation mechanism that allows partial recovery of the developing $\mathrm{CB}$ after genetic depletion of the EGL.

\section{Wild type cells replenish the anterior EGL of Atoh1-Gli2 CKOs}

Since the final size of the $\mathrm{CB}$ is largely dependent on the expansion of the EGL, we analyzed Atoh1-Gli2 CKO 


\section{a}

Atoh1-FIpoER
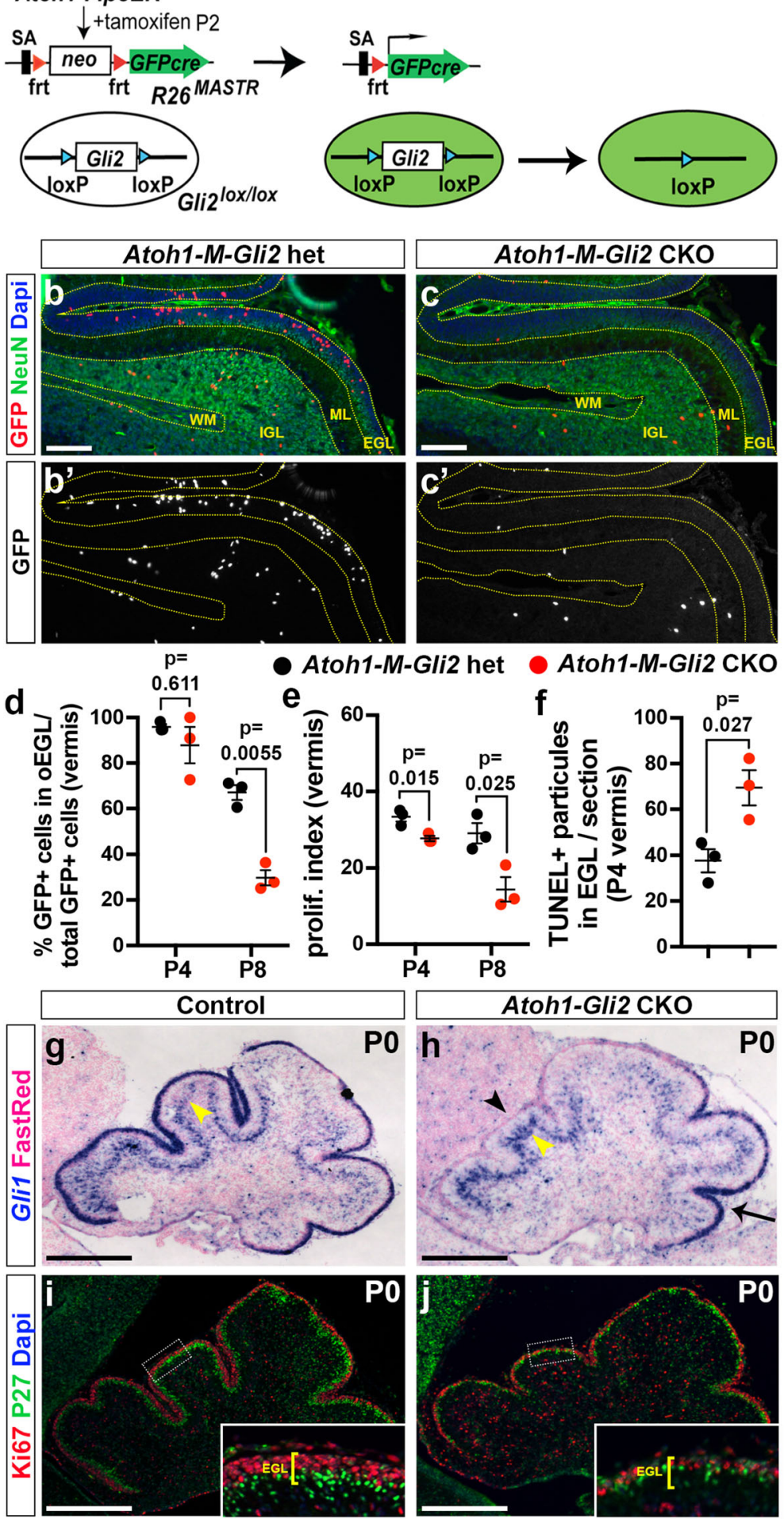

Fig. 1 (See legend on next page.) 
(See figure on previous page.)

Fig. $1 \mathrm{HH}-$ GLI2 signaling maintains GCP in an undifferentiated state and promotes their survival. a Schematic representation of the MASTR approach. The R26 MASTR allele expresses a GFPcre fusion upon Flp induced deletion of a neo (STOP) cassette. When the R26 $6^{\text {MASTR }}$ allele and the Atoh1-FlpoER transgene are combined with a floxed gene such as Gli2, recombination of the loxP sites occurs in >98\% of GFP + cells within 3 days of administrating tamoxifen ( $(\mathrm{m})$ at $\mathrm{P} 2$. The mutant cells and their progeny can subsequently be identified by the continuous expression of eGFP from the R26 allele. b-c Fluorescent Immuno-Histo-Chemical (FIHC) detection of the indicated proteins and dapi on mid-sagittal sections (lobule VII and VIII) of P8 control R26 $6^{\text {MASTR/+ }}$; Atoh1-FlpoER/+; Gli2lox/+ (Atoh1-M-Gli2 het, b) and R26 MASTR/+; Atoh1-FlpoER/t; Gli2 ${ }^{\text {lox/lox }}$ (Atoh1-M-Gli2 CKO, c) mice treated Tm at P2. $\mathbf{d}$-f Graphs of the proportion of GFP+ cells in the outer (o) EGL at P8 $(n=3)(\mathbf{d})$, the proliferation index at P8 (\% $[\mathrm{GFP}+\mathrm{EdU}+]$ cells of all $[\mathrm{GFP}+]$ cells in the oEGL) $(n=3)(\mathbf{e})$ and the number TUNEL+ particles per section at P4 $(n=3)(\mathbf{f})$ in Atoh $1-\mathrm{M}-\mathrm{Gli}$ het (control, black) and R26 MASTR/+ ; Atoh1-FlpoER/+; Gliz ${ }^{\text {loxlox }}$ (Atoh1-M-Gli2 CKO, red) mice treated with Tm at P2. All of the analyses were performed on 3 midline sections per brain. All graphical data are presented as means \pm SEM and significance determined using two-tailed T-test. $\mathbf{g}$-h In situ hybridization of Gli1 mRNA on P0 mid-sagittal cerebellar sections of Gli2 ${ }^{\text {lox/lox }}$ (control, g) and Atoh1-Cre/t; Gliz ${ }^{\text {loxlox }}$ (Atoh1-Gli2 CKO, h) mice. Black arrowhead indicates the loss of Gli1 expression in the anterior mutant EGL, black arrow Gli1 remaining in the posterior EGL and yellow arrowheads indicate Gli1 expression in Bergmann glia in the Purkinje Cell Layer (PCL). $\mathbf{i}-\mathbf{j}$ FIHC detection of the indicated proteins and dapi on P0 mid-sagittal cerebellar sections of Gli2 ${ }^{\text {lox/lox }}$ (control, i) and Atoh1-Cre/t; Gli2 ${ }^{\text {loxlox }}$ (Atoh1-Gli2 CKO, j) mice. High power images are shown of the areas indicated by white rectangles and the thickness of the EGL is indicated by yellow bracket. Scale bars represent $100 \mu \mathrm{m}(\mathbf{b}-\mathbf{c})$ and $500 \mu \mathrm{m}(\mathbf{g}-\mathbf{j})$

cerebella at P8 when the EGL is normally thick. Similar to our previous study using irradiation at P1 [25], the EGL was replenished with proliferating cells by P8 in Atoh1-Gli2 CKO animals. We therefore performed in situ hybridization (ISH) and analyzed the expression of Gli1. Although Gli1 expression was greatly diminished at P0 (Fig. 1h), the EGL of P8 Atoh1-Gli2 CKOs exhibited Gli1 expression throughout the anterior EGL, comparable to that observed in control animals and the posterior EGL of mutants (Fig. 4a-b). In addition and unlike at P0, no difference in Gli1 expression was observed in the PCL at P8 (Fig. 4a-b). Moreover, Gli1+ cells expanded in the EGL, as revealed by the proliferation maker Ki67 (Fig. 4c-d). We measured the thickness of the EGL and found no significant difference between control and Atoh1-Gli2 CKO P8 animals $(n=4 ; 0.044 \pm$ $0.0025 \mathrm{~mm}$ vs $0.0399 \pm 0.0023 \mathrm{~mm}$ ) (Fig. 4e). However we observed a significant increase in the size of the

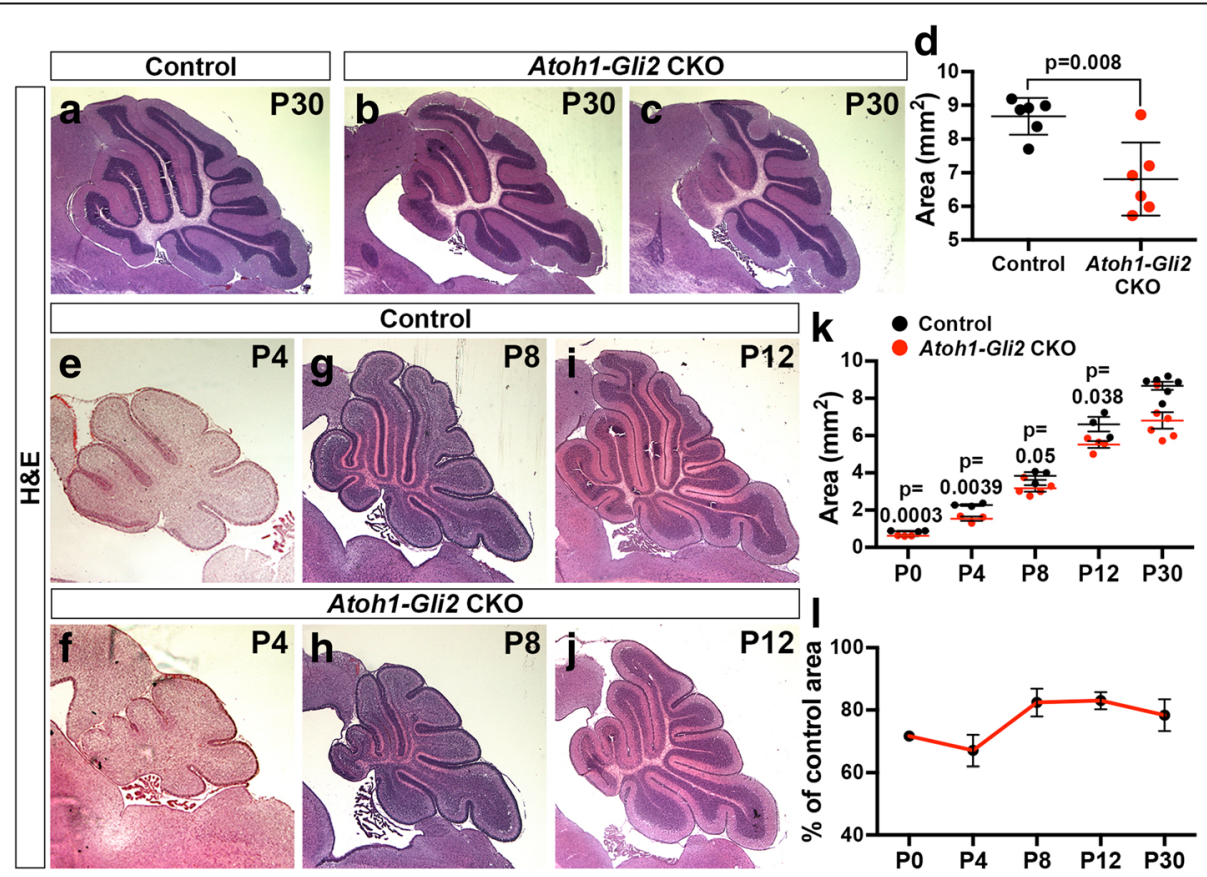

Fig. 2 The size of the cerebellum partially recovers in Atoh-Gli2 CKOs over time. a-c Mid-sagittal sections of P30 Gli2 ${ }^{\text {lox/lox }}$ (control, a) and Atoh 1Cre/t; Gli2 ${ }^{\text {lox/lox }}$ (Atoh1-Gli2 CKO, b-c) cerebella stained with Hematoxilin and Eosin (H\&E). d Graph of the area of mid-sagital CB sections of P30 Gliz2 ${ }^{\text {loxlox }}$ (control, black) $(n=6)$ and Atoh1-Cre/t; Glizlox/lox (Atoh1-Gli2 CKO, red) $(n=6)$ mice. e-j Mid-sagittal CB sections of P4 (e-f), P8 (g-h) and P12 (i-j) Glizex/lox (control, e, $\mathbf{g}$ and $\mathbf{i}$ ) and Atoh1-Cre/t; Gli2 ${ }^{\text {lox/lox }}$ (Atoh1-Gliz CKO, $\mathbf{f}, \mathbf{h}$ and $\mathbf{j}$ ) mice stained with H\&E. $\mathbf{k}$ Graph of the area of 3 midsagital sections of Gli2 ${ }^{\text {lox/lox }}$ (control, PO: $n=3$, P4: $n=3$, P8: $n=3$, P12: $n=3$ and P30: $n=6$ ) and Atoh1-Cre/+; Gli2 ${ }^{\text {loxlox }}$ (Atoh1-Gli2 CKO, P0: $n=3$, P4: $n=3$, P8: $n=6$, P12: $n=4$ and P30: $n=6$ ) cerebella. I Graph showing the decrease in area of 3 mid-sagital sections of Atoh1-Gli2 CKO cerebella as a percentage of controls during development. All graphical data are presented as means \pm SEM and significance determined using two-tailed T-test. Scale bars represent $1 \mathrm{~mm}$ 


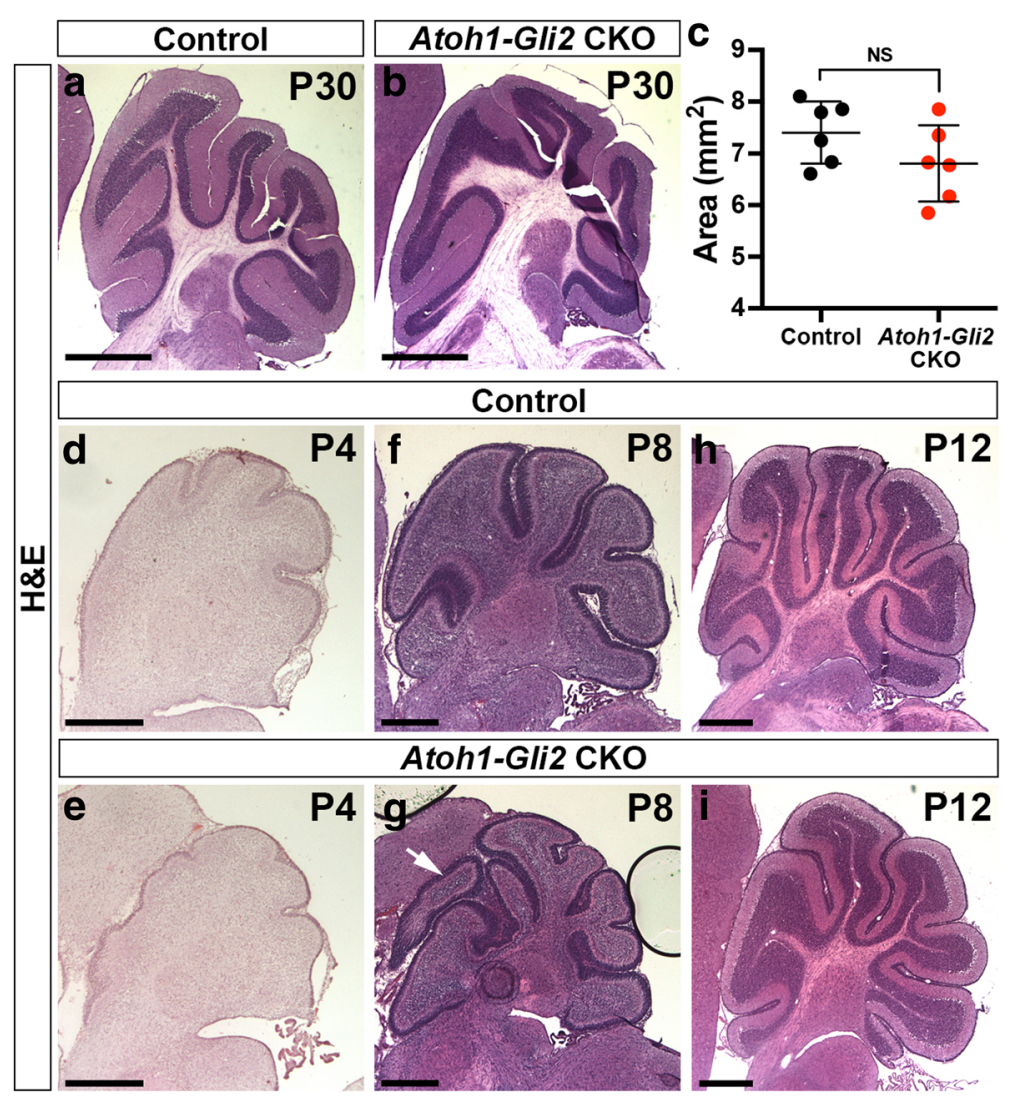

Fig. 3 Hemispheres recover better than the vermis in Atoh1-Gli2 CKO mice. a-b Hemispheric sagittal sections of P30 Gli2 ${ }^{\text {lox/lox }}$ (control, a) and Atoh1-Cre/+; Gli2 ${ }^{\text {loxlox }}$ (Atoh1-Gli2 CKO, b) cerebella stained with Hematoxilin/Eosin (H\&E). c Graph of the area of hemispheric sagital sections of P30 Gli2 loxlox (control, black) $(n=6)$ and Atoh1-Cre/+; Gliz ${ }^{\text {loxlox }}$ (Atoh1-Gli2 CKO, red) $(n=6)$ CB. (d-i) Hemispheric sagittal sections of P4 (d-e), P8 (fg) and P12 (h-i) Gli2 ${ }^{10 x / 10 x}$ (control, d, f and h) and Atoh1-Cre/t; Gli2 ${ }^{\text {lox/lox }}$ (Atoh1-Gli2 CKO, e, g and i) cerebella stained with H\&E. White arrow indicates the presence of extra folia. Scale bars represent $1 \mathrm{~mm}(\mathbf{a}-\mathbf{b})$ and $500 \mu \mathrm{m}(\mathbf{b}-\mathbf{c}$ and $\mathbf{d}-\mathbf{i})$

outer EGL (oEGL) by seemingly delaying their differentiation compared to controls as revealed by the increase [oEGL/EGL area] ratio $(n=4 ; 68.91 \pm 2.44 \%$ vs $53.85 \pm$ 0.94\%) (Fig. 4f). Analysis of Cre expression revealed that only a small subset of cells in the anterior EGL expressed $\mathrm{Cre}$ in the anterior $\mathrm{CB}$ compared to controls (Atoh1-Cre/+; Gli2 $2^{\text {flox/+ }}$ or Atoh1-Gli2 het) (Fig. 4g-h). Consistent with the presence of wild type (WT) cells in the EGL, GLI2 protein was detected in most cells in the EGL (Fig. 4i-i'). Interestingly, GCPs in the partially rescued anterior EGL expressed a low level of the stem cell marker SOX2 at P8, something that was never observed in control animals (Fig. 4j-k). Interestingly, TUNEL analysis showed a significant increase of cell death in the replenished P8 EGL compared to controls $(n=4 ; 459.9$ \pm 85.39 vs $89.52 \pm 17,73$ particles per $\mathrm{mm}^{2}$ of EGL) (Additional file 3: Figure S3a-c) suggesting that some GCPs in the EGL of Atoh1-Gli2 CKOs that expressed the EGL marker Atoh1 (as shown by Atoh1-GFP staining, Additional file 3: Figure S3c) turn on Atoh1-Cre and die because they lack Gli2. Thus, the reduction of GCPs in the EGL of Atoh1-Gli2 CKOs at P0 stimulates a compensation process that leads to replenishment of the GCPs by WT cells.

\section{NEPs switch their fate to become GCPs and produce GCs} in Atoh1-Gli2 CKO cerebella

Our previous study demonstrated that SOX2+ NEPs can migrate to the EGL after injury and then turn off SOX2 and turn on Atoh1 [25], and our present results revealed that some cells in the rescued EGL in P8 Atoh1-Gli2 CKO cerebella express a low level of SOX2. We thus hypothesized that WT NEPs (SOX2+) are able to change their fate to become GCPs and replenish the EGL as part of a compensation mechanism in Atoh1-Gli2 CKOs. Using a Nestin-FlpoER transgene [40] and a Flippase (Flp)-dependent R26 reporter allele that expresses TDTom, we performed genetic inducible fate mapping (GIFM) of NEPs in the Atoh1-Gli2 CKO cerebella. In contrast to P30 controls (Nestin-FlpoER/+; $R 26^{\text {frt-STOP-frt-TDTom } /+}$ or Nes-TDTom mice administrated Tm at P0), we observed many TDTom+ cells 

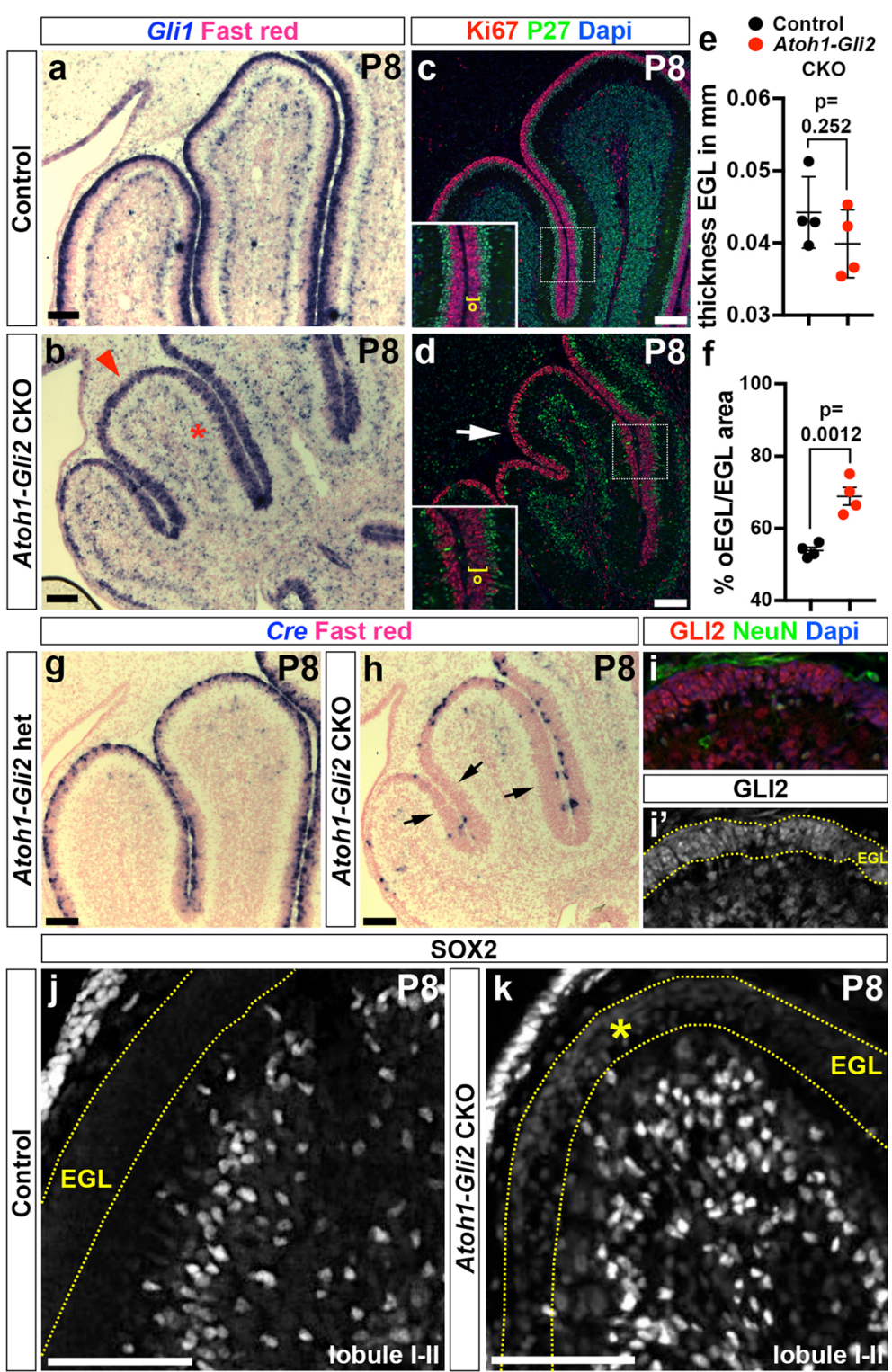

Fig. 4 Loss of Gli2 mutant GCPs at P0 is compensated by wild type (WT) cells at P8. a-b In situ RNA hybridization analysis of Gli1 on P8 midsagittal cerebellar sections of Gli2 ${ }^{\text {lox/lox }}$ (control, a) and Atoh1-Cre/t; Gli2 ${ }^{\text {loxlox }}$ (Atoh1-Gli2 CKO, b) mice. Red arrowhead indicates the strong Gli1 expression in the mutant EGL and red asterisks indicate normal Gli1 expression in Bergmann glia in the Purkinje Cell Layer (PCL). $\mathbf{c}-\mathbf{d}$ FIHC detection of the indicated proteins and dapi on P8 mid-sagittal cerebellar sections of Gli2 ${ }^{\text {lox/lox }}$ (control, c) and Atoh1-Cre/t; Gli2 ${ }^{\text {lox/lox }}$ (Atoh 1-Gli2 $\mathrm{CKO}, \mathbf{b})$ mice. High power images are shown of the areas indicated by white rectangles in (c and $\mathbf{d}$ ) with the thickness of the outer EGL (o) indicated by yellow brackets. The white arrow in (b) indicates the proliferating EGL. e and $\mathbf{f}$ Graphs of the thickness proportion of the EGL at P8 $(n=4)(\mathbf{e})$ and the proportion of oEGL area at P8 (\% [oEGL] area of total [EGL] area) $(n=4)(\mathbf{f})$ in Gli2 ${ }^{\text {lox/lox }}\left(\mathrm{CTL}\right.$, black) and Atoh 1-Cre/+; Gliz $2^{\text {lox } / 10 x}$ (Atoh1-Gli2 CKO, red) mice. All of the analyses were performed on 3 midline sections per brain. All graphical data are presented as means \pm SEM and significance determined using two-tailed T-test. $\mathbf{g}$-h In situ hybridization of Cre RNA on P8 midsagittal cerebellar sections of Gli2 ${ }^{\text {lox/lox }}$ (control, $\mathbf{g}$ ) and Atoh1-Cre/t; Gli2 ${ }^{\text {lox/lox }}$ (Atoh 1-Gli2 CKO, h) mice. Black arrows indicate the loss of Cre expression in the partially rescued EGL. i-k FIHC detection of the indicated proteins and dapi on P8 mid-sagittal cerebellar sections of Gli2 ${ }^{\text {lox/ox }}$ (control, j) and Atoh1-Cre/t; Gli2 ${ }^{\text {loxlox }}$ (Atoh1-Gli2 CKO, i and k) mice. EGL is indicated by the yellow dotted lines and yellow asterisk indicates low level of SOX2 expression in the mutant EGL. Scale bars represent $100 \mu \mathrm{m}$

that also expressed the GC marker NeuN in the IGL of Atoh1-Gli2 CKO mutants $(n=6)$ (Fig. 5a-f). Interestingly, the vermis of P30 Atoh1-Gli2 CKOs that recovered well showed an apparently greater contribution of NEP-derived TDTom+ cells in the IGL than those mice that recovered poorly (compare Fig. 5c-d to e-f). Similar results were obtained when analyzing the hemispheres (Additional file 4: Figure S4). However, and consistent with our analysis of $\mathrm{CB}$ size, there appeared to be less variability in the percentage of TDTom + cells 


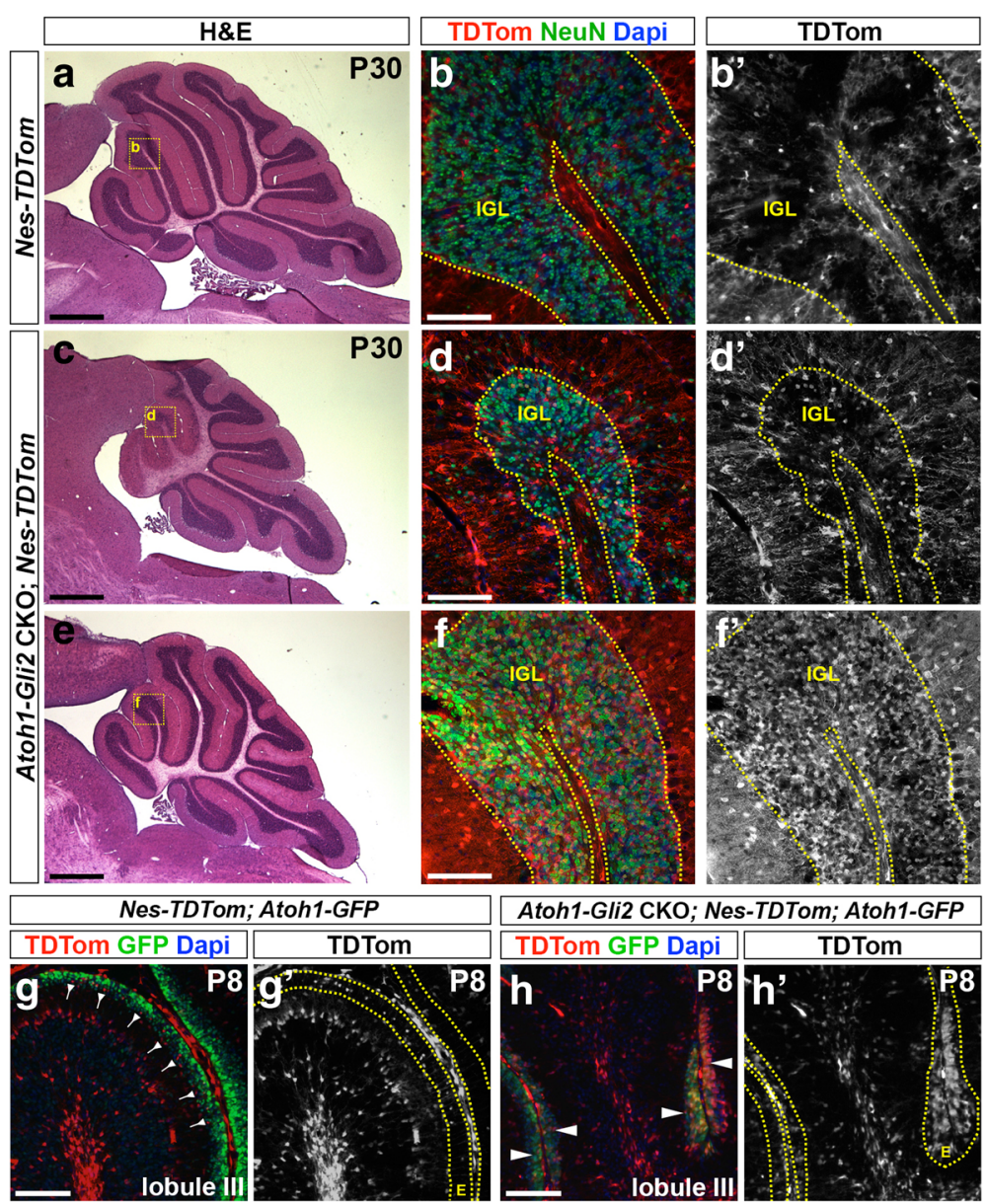

Fig. 5 Nestin-Expressing Progenitors (NEPs) populate the EGL, express GCP markers and produce granule cells in response to loss of Gli2 in the EGL. a, $\mathbf{c}$ and e H\&E staining of sagittal sections of the vermis of P30 Nes-FlpoER/t; R26 FSF-TDTom/t (Nes-TDTom, a) and Atoh1-Cre/t; Gli2 ${ }^{\text {lox/lox; }}$; NesFlpoER/+; R26 FSF-TDTom/+ (Atoh1-Gli2 CKO; Nes-TDTom, $\mathbf{c}$ and $\mathbf{e}$ ) mice injected with Tm at PO. $\mathbf{b}, \mathbf{d}$ and $\mathbf{f}$ FIHC detection of the indicated proteins and dapi on mid-sagittal cerebellar sections at P30. High power images are shown of the areas indicated by yellow rectangles in (a, c and e). IGL is outlined by yellow dotted lines. $\mathbf{g}$-h FIHC detection of the indicated proteins and dapi on mid-sagittal cerebellar sections (lobule III) of P8 NesFlpoER/+; R26 FSF-TDTom/+; Atoh1-GFP/+ (Nes-TDTom; Atoh1-GFP, g) and Atoh1-Cre/+; Gli2 lox/lox; Nes-FlpoER/+; R26 FSF-TDTom/+/+; Atoh1-GFP/+ (Atoh1-Gli2 CKO; Nes-TDTom; Atoh1-GFP, h) mice injected with Tm at PO. The EGL (E) is outlined by yellow dotted lines. Backward arrows indicate TDTom+ and Atoh1-GFP- cells in the inner EGL. White arrowheads indicate TDTom+ and Atoh1-GFP+ cells in the inner EGL. Scale bars represent $1 \mathrm{~mm}(\mathbf{a}$, c and $\mathbf{e})$ and $100 \mu \mathrm{m}(\mathbf{b}, \mathbf{d}, \mathbf{f}, \mathbf{g}$ and $\mathbf{h}$ )

observed in the hemispheres compared to the vermis. Analysis of the vermis at P8 showed a significant increase in the number of Nestin-derived TdTom+ cells in the EGL compared to controls $(n=3 ; 3049 \pm 713.6$ vs $308.8 \pm 121$ TDTom + cells per $\mathrm{mm}^{2}$ of EGL; $p=0.0193$ ) (Fig. 5g-h). Furthermore, TDTom+ cells in the P8 EGL already expressed the GCP marker Atoh1 (as shown by Atoh1-GFP staining) $(n=3 ; 80.92 \pm 3.69$ vs $1.74 \pm 1.11 \%$ of TDTom + Atoh1-GFP+/ total TDTom+ cells in the EGL; $p<0.0001$ ) (Fig. 5g-h).

A subset of proliferating PCL NEP-derived cells migrate to the IGL in Atoh1-Gli2 CKO cerebella

We next analyzed the behavior of NEPs using a Nes-CFP reporter line [43]. Consistent with our GIFM experiment and unlike control animals (Nes-CFP), the EGL of Atoh1-Gli2 CKOs expressed a high level of CFP (Fig. 6a-b). Surprisingly, streams of CFP+ cells were seen in lobule 3 spanning between the IGL and EGL that were not present in controls (Fig. 6a-b) or in irradiated mice [25]. Interestingly, some cells in the streams expressed the proliferation maker Ki67 as well as the GCP/GC marker PAX6 (Fig. 6c-d) suggesting that a subset of NEP-derived cells were not able to stay in the EGL and thus migrated back to the cerebellar cortex. To test this idea we performed live imaging of P8 Nes-CFP cerebellar slice cultures from both control and Atoh1-Gli2 CKOs (Atoh-Gli2 CKO; Nes-CFP). Strikingly, by tracking the movement of individual cells during $\sim 6 \mathrm{~h}$ of imaging we observed Nes-CFP+ cells actively migrating from the PCL to the EGL in slices from Atoh-Gli2 


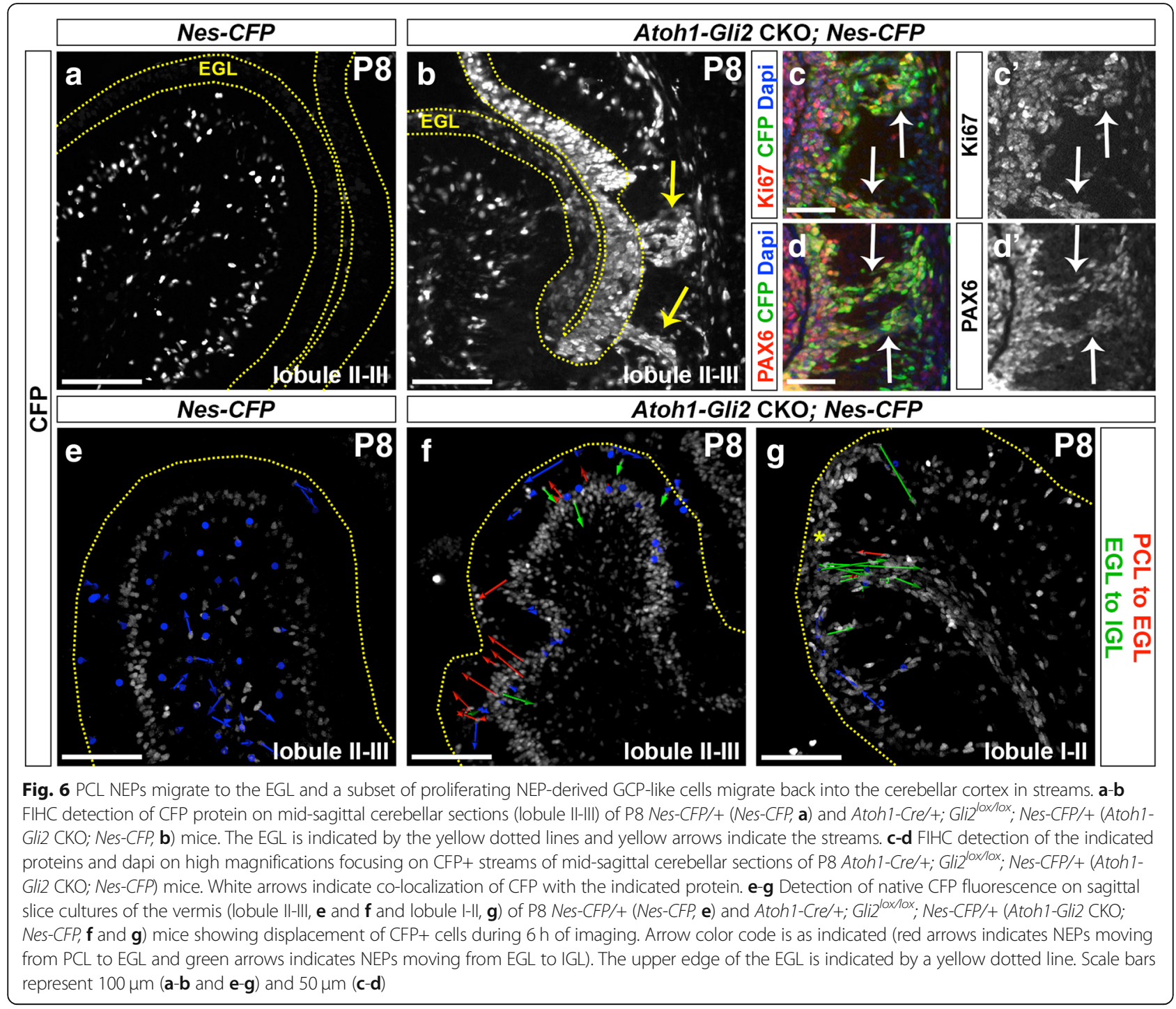

CKO cerebella but not control mice at P8 (Fig. 6e-f and Additional file 5: Video S1 and Additional file 6: Video S2). The CFP+ layer of cells also appeared thicker in the mutants, indicating the NEPs expanded in number. Interestingly, in the areas containing streams of CFP+ cells the majority of cells that were tracked moved in the opposite direction from the EGL to the IGL (Fig. $6 \mathrm{~g}$ and Additional file 7: Video S3). Our live imaging experiments thus provide evidence that NEPs located in the PCL expand and then migrate to replenish the EGL in response to GCP-specific loss of Gli2. Furthermore, a subset of NEP-derived cells is not able to integrate into the EGL and migrate back down to towards the cerebellar cortex.

Gli2 CKO in NEPs inhibits the recovery of the EGL in Atoh1-Gli2 CKOs

Since we have shown previously that $\mathrm{SHH}$ signaling $(\mathrm{Smo})$ is necessary in NEPs for CB recovery following irradiation, we tested whether Gli2 plays a role in this process. We generated littermates of 4 different genotypes that were administered $\mathrm{Tm}$ at $\mathrm{P} 0$, and analyzed each genotype $(n=3)$ at P8, P12 and P21: Gli2 $2^{\text {flox flox }}$ WT (control) mice, Nestin-FlpoER/+; R26 ${ }^{\text {MASTR/+; }}$ Gli2 $2^{\text {flox/flox }}$ single (Nes-Gli2 CKOs mutants lacking Gli2 in NEPs), Atoh1-Cre/+; Glif flox/flox single (Atoh1-Gli2 CKOs lacking Gli2 in anterior GCPs) and Nestin-FlpoER/+; R26 $6^{\text {MASTR/++ }}$; Atoh1-Cre/+; Gli2 $2^{\text {flox/flox }}$ double (Atoh1-NesGli2 CKOs lacking Gli2 in NEPs and GCPs) mutants. We did not observe any obvious phenotype in the Nes-Gli2 CKOs at all stages compared to controls (compare Fig. 7c-d to $\mathrm{a}-\mathrm{b}$, Additional file 8: Figure S5c-d to a-b and Fig. 8d to a). However, $\mathrm{H} \& \mathrm{E}$ staining revealed that the anterior $\mathrm{CB}$ appeared reduced in the double mutants (Atoh1-Nes-Gli2 CKOs) compared to Atoh1-Gli2 CKOs at both P8 and P12 (compare Fig. 7e to g and Additional file 8: Figure S5e to g). Analysis of proliferating GCPs in the outer EGL (Ki67+) 


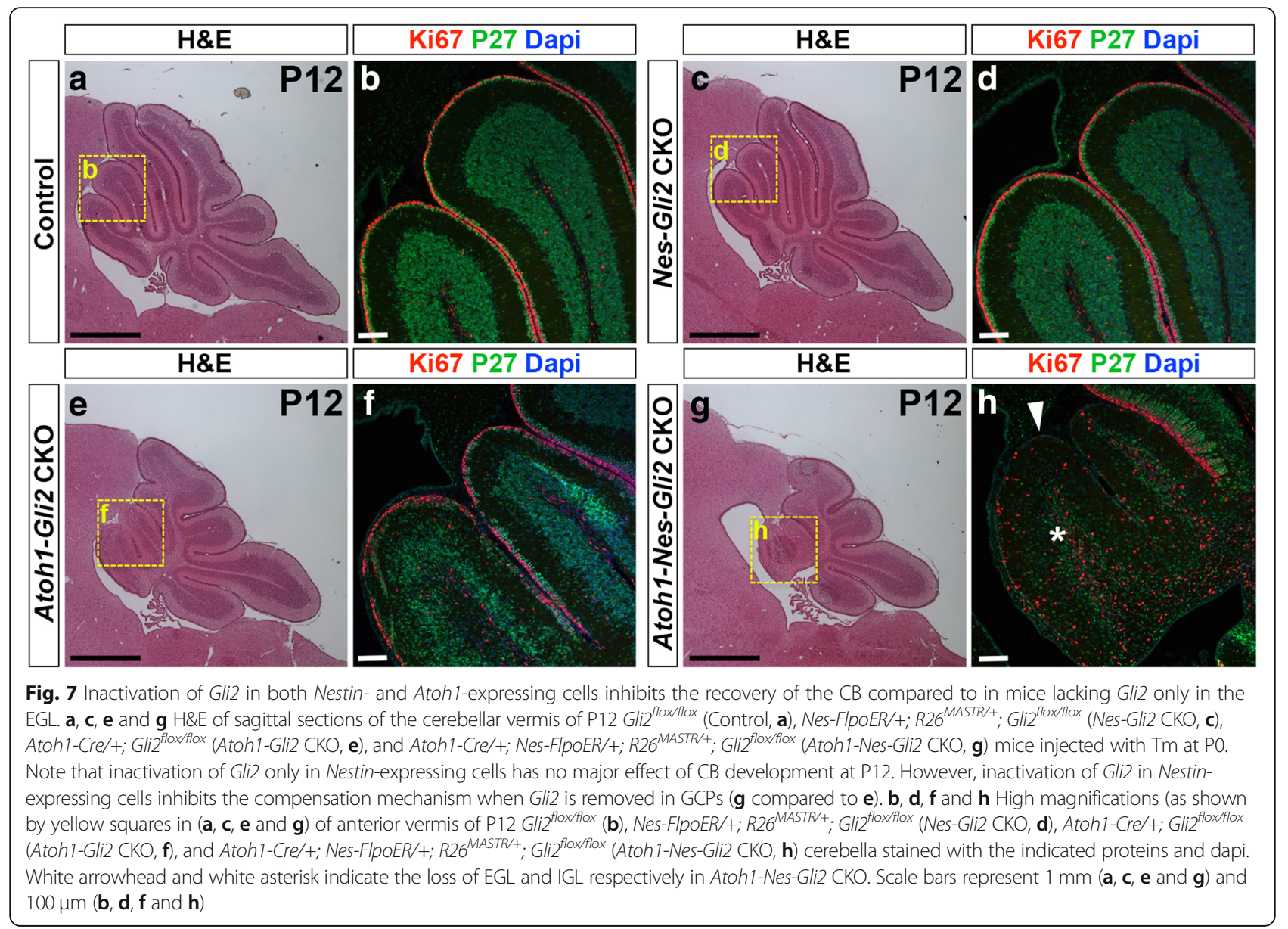

and post mitotic GCs in the inner EGL and IGL (P27+) at both stages showed that the anterior EGL appeared more depleted in Atoh1-Nes-Gli2 CKO compared to Atoh1-Gli2 CKO cerebella and that Atoh1-Nes-Gli2 CKO animals failed to form a proper P27+ inner EGL and IGL (compare Fig. $7 \mathrm{f}$ to $\mathrm{h}$ and Additional file 8: Figure S5f to h). Analysis of the fate of GFP+ Nestin-expressing cells in P21 Atoh1-Nes-Gli2 CKOs using a Flp-mediated R26 reporter allele that expresses nuclear $\beta$ Galactosidase (Bgal) $\left(R 26^{\text {frt-STOP-frt-lacZ/+ }}\right)$ revealed that unlike Atoh1Gli2 CKOs in which Nestin-derived GCs populated the IGL (Figs. 5a-f and 8c), the Gli2 mutant Nestin-derived cells populated the IGL poorly (Fig. 8f). The few GFP+ cells in the IGL of the double mutants were likely interneurons or astrocytes.

These results demonstrate that $\mathrm{SHH}$-signaling through GLI2 plays a crucial role during NEP-mediated cerebellar recovery from loss of GCPs.

\section{Discussion}

In this study we developed a conditional mutant strategy to delete Gli2 (the gene encoding the major effector of SHH signaling) in most GCPs in the anterior cerebellum using an Atoh1-Cre transgene used in many studies (e.g. [41, 45-52]). Although we show using a mosaic analysis that SHH-GLI2 signaling is crucial for generating the correct pool of GCs by promoting GCP viability and proliferation, deletion of Gli2 in the EGL using this transgene is not sufficient to induce a major hypoplasia of the adult cerebellum in most mutants. We discovered that although the GCP pool is greatly diminished in Atoh1-Gli2 neonates, it is subsequently replenished by a cellular mechanism that includes adaptive reprogramming of WT NEPs to become GCPs. Importantly, since the transgene does not turn on in many of the newly generated GCPs, the EGL recovers and generates GCs. Rare GCPs that never express Cre could also contribute to replenishment of the GCPs if they can undergo more rounds of cell division than normal.

A question raised by this and previous studies is what signals induce the NEPs that reside in the PCL to change their fate and become GCPs. It was previously shown that when irradiation is used to kill most GCPs at P2-3, NEPs contribute to replenishment of the EGL [25]. It is therefore possible that in Atoh1-Gli2 mutants a signal associated with the cell death we observed triggers NEPs to change their fate and generate GCPs. An alternative 


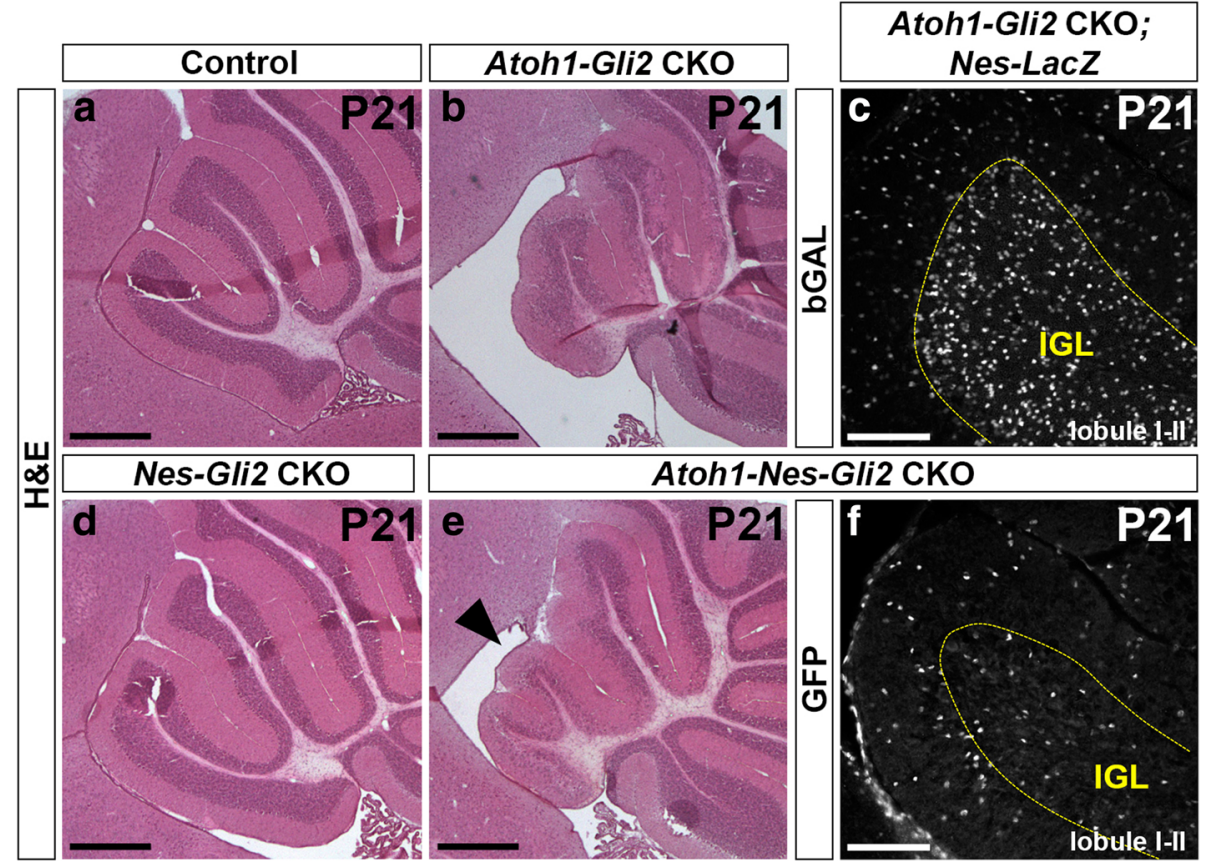

Fig. 8 NEP-derived cells failed to populate the IGL at P21. $\mathbf{a}, \mathbf{b}, \mathbf{d}$ and $\mathbf{e}$ H\&E staining of sagittal sections of anterior cerebellar vermis of P21 Gli2 ${ }^{\text {floxflox }}$ (Control, a), Atoh1-Cre/t; Gli2 floxflox (Atoh1-Gli2 CKO, b), Nes-FlpoER/t; R26 $6^{\text {MASTR/t; }}$;li2 ${ }^{\text {floxflox }}$ (Nes-Gli2 CKO, d) and Atoh1-Cre/t; Nes-FlpoER/

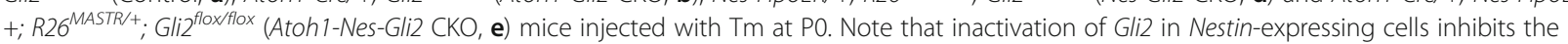
compensation mechanism in the anterior vermis (black arrowhead in $\mathbf{e}$ ). $\mathbf{c}$ and $\mathbf{f} \mathrm{FIHC}$ detection of the indicated proteins on mid-sagittal cerebellar sections (lobule I-II) of P21 Atoh1-Cre/t; Gli2 floxflox; Nes-FlpoER/t; R26 FSF-LacZ/t+ (Atoh1-Gli2 CKO; Nes-LacZ, c) and Atoh1-Cre/t; Nes-FlpoER/ +; R26 $6^{\text {MASTR/+ }}$; Gliz floxfllox (Atoh1-Nes-Gli2 CKO, f) mice injected with Tm at P0. IGL is indicated by the yellow doted line. Scale bars represent $500 \mu m$ $(\mathbf{a}, \mathbf{b}, \mathbf{d}$ and $\mathbf{e})$ and $100 \mu \mathrm{m}(\mathbf{c}$ and $\mathbf{f})$

mechanism is that the depletion of the EGL results in a change in Purkinje cell signaling, possibly because of a reduction in excitatory input since less granule cells are generated. In turn, $\mathrm{SHH}$ might preferentially accumulate in the cell bodies of Purkinje cells, which lie close to the NEPs, thus increasing HH signaling to NEPs [25]. Consistent with a role for GCs in regulating NEP behaviors, the Atoh1-Cre transgene is first expressed in GCPs at E13.5 [45], but the replenishment of the EGL in Atoh1-Gli2 CKOs only occurs several days after the EGL is depleted and when the IGL normally first becomes apparent (P3-P4). Thus, a possible involvement of NEPs in a compensation processes should be considered for conditional mutants that alter not only GCP proliferation and survival, but also genes involved in differentiation of GCs.

It might be expected that Atoh1-Smo CKOs would have a similar phenotype to Atoh1-Gli2 CKOs, given that both genes are required for SHH signaling. However, Atoh1$C r e E R /+; S m o o^{l o x P / \Delta}$ mice in which one allele of the Smoothened gene is deleted in the germline and deletion of the floxed allele is dependent on tamoxifen (Tm) administration have a severe cerebellum hypoplasia [13]. A possible explanation for the phenotype in such mutants is that reprogramming of NEPs in Smo heterozygous mutants is partially compromised since $\mathrm{HH}$ signaling is crucial for the expansion of PCL NEPs and their migration to the EGL [25]. In addition, since Tm diminishes cerebellum recovery after EGL depletion [25], the combination of a lower level of SMO protein in NEPs and administration of Tm to Atoh1-CreER/+; Smo ${ }^{\operatorname{loxP} / \Delta}$ mice might blunt the response of NEPs to Smo-dependent depletion of the EGL leading to severe hypoplasia.

We observed a large variability in the vermal hypoplasia of Atoh1-Gli2 CKO adults, suggesting that only some mutant cerebella can efficiently recover. The variability in recovery is likely because the degree to which the Atoh1-Cre transgene is turned on in newly formed WT GCPs varies between mice. Since loss of Gli2 leads to cell death, the TUNEL staining observed in the EGL of P8 Atoh1-Gli2 CKO cerebella is consistent with Gli2 being deleted after P6 in some new wild type GCPs that are either derived from NEPs or rare GCPs that had not previously expressed Atoh1-Cre. In addition, our experiments indicate that some NEPs that enter the EGL and turn on PAX6 migrate back towards the IGL before becoming postmitotic and turning off Nes-CFP. We hypothesize that some NEP-derived GCPs that undergo deletion of Gli2 after entering the EGL survive but are unable to fully reprogram into GCPs. An interesting gene that might not be properly turned on is $C x c R 4$, since SDF1 expressed by 
meninges signals through CXCR4 to maintain GCPs in the outer EGL and to enhance SHH-dependent proliferation [53]. Furthermore, SHH-GLI1 signaling induces the transcription of $\mathrm{Cxcr} 4$ and $\mathrm{Cxcr} 7$ [54]. We propose that in Atoh1-Gli2 CKOs a subset of PCL-derived NEPs express CRE after entering the EGL, and the subsequent loss of GLI2 protein reduces CXCR4, leading to migration of proliferating GCP-like cells back into the cerebellar cortex. Thus, the variable extent of growth of the cerebellum in Atoh1-Gli2 CKOs likely results from the amount of Atoh1-Cre induced after P4 in GCPs, and the resulting balance of cell death and premature migration from the EGL.

The cerebellum is broadly divided along the mediolateral axis into a central vermis and two lateral hemispheres [19]. Although recovery from depletion of the EGL at P0 occurs in both regions of Atoh1-Gli2 CKOs, the recovery is more robust in the hemispheres. Curiously, the hemispheres of Atoh1-Gli2 CKOs exhibit extra folds at P8 (arrow in Fig. 3g), suggesting a differential recovery response along the medio-lateral axis. The vermis and hemispheres are molecularly and functionally distinct $[19,55]$, and hemispheric GCPs have a higher sensitivity to high-level SHH-signaling than those in the vermis [55]. We propose that hemispheric NEP-derived GCPs in the EGL maintain a higher level of SHH signaling and therefore expand more rapidly and efficiently than those in the vermis.

\section{Conclusion}

In this study, we show that the ability of NEPs to compensate for postnatal cerebellar damage must be considered in the interpretation of any mutant phenotype where genes involved in EGL cell proliferation/differentiation and survival have been disrupted. This is particularly the case if the Atoh1-Cre transgene utilized in this study [41] is employed to generate conditional mutants. Compensation for a loss of GCPs is most likely to occur for genes that are required after birth, once NEPs are present. Finally, our findings raise the question of whether similar recovery phenomena occur in other regions of the brain, and depending on the transgene used could complicate interpretation of mutant phenotypes.

\section{Additional files}

Additional file 1: Figure S1. Similar to in the vermis, SHH-Gli2 maintains GCP in an undifferentiated state and promotes their survival in the hemispheres. (a) Graphs of the number of GFP+ cells in the outer (o) EGL at P4 $(n=3)$ and P8 $(n=3)$ in both hemispheres and vermis of R26 $6^{\text {MASTRA+ }}$.

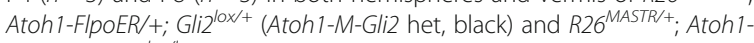
FlpoER/t; Gli2 ${ }^{\text {loxllox }}$ (Atoh1-M-Gli2 CKO, red) mice treated with Tm at P2. (b-d) Graphs of the proportion of CFP+ cells in the outer (o) EGL at P8 ( $n$ $=3)(b)$, the proliferation index at P8 (\% [GFP+ EdU+] cells of all [GFP+] cells in the oEGL) $(n=3)(c)$ and the number of TUNEL+ particles per section at P4 $(n=3)(\mathrm{d})$ in the hemispheres of R26 $6^{\text {MASTR/+ }}$; Atoh 1-FlpoER/+; Gli2 ${ }^{\text {lox/+ }}$ (Atoh1-M-Gli2 het, black) and R26 $6^{\text {MASTR/+}}$; Atoh 1-FlpoER/t; Gli2 ${ }^{\text {lox/lox }}$ (Atoh T-M-Gli2 CKO, red) mice treated with Tm at P2. All of the analyses were performed on 3 sections per region and per brain. All graphical data are presented as means \pm SEM and significance determined using twotailed. (JPG $238 \mathrm{~kb}$ )

Additional file 2: Figure S2. GLI2 protein is lost in the P0 Atoh1-Gli2 CKO EGL. (a and d) In situ hybridization of Cre mRNA on PO mid-sagittal cerebellar sections of Gliz ${ }^{\text {loxlox }}$ (control, a) and Atoh 1-Cre/t; Gliz $2^{\text {loxlox }}$ (Atoh1-Gli2 CKO, d) mice. Black arrows indicate the lack of Cre expression in the most posterior part of the CB. (b-c and e-f) FIHC detection of GLI2 protein and dapi in the indicated regions (as shown by black squares in a and d) in PO Gli2 lox/lox (control, b-c) and Atoh1-Cre/t; Gli2 lox/lox (Atoh1-Gli2 CKO, e-f) CB. Yellow arrowhead in e and white arrow in $F$ indicate respectively the absence and presence of GLI2 protein in the EGL. Scale bars represent $1 \mathrm{~mm}$ ( $a$ and d) and $100 \mu \mathrm{m}$ (b-c and e-f). (JPG $1811 \mathrm{~kb}$ )

Additional file 3: Figure S3. Rescued EGL still exhibits an increase in cell death. (a-b) TUNEL and dapi detection on mid-sagittal sections of P8 Gliz'loxlox (Control) and Atoh1-Cre/t; Gli2 ${ }^{\text {loxlox }}$ (Atoh1-Gli2 CKO) CB. White arrows indicate the presence of the EGL (b). (c) Graphs of the number of TUNEL+ particles per $\mathrm{mm}^{2}$ of EGL $(n=4)$ in the vermis (lobule I to $\mathrm{V}$ ) of P8 Gli2 ${ }^{\text {lox/lox }}$ (Control, black) and Atoh1-Cre/t; Gliz'lox/lox (Atoh1-Gli2 CKO, red) $C B$. All of the analyses were performed on 3 sections per region and per brain. All graphical data are presented as means \pm SEM and significance determined using two-tailed test. (d) Detection of native GFP fluorescence and in situ hybridization of Cre mRNA on a mid-sagittal section (lobule II-III) of a P8 Atoh1-Cre/+; Gli2lox/lox; Atoh1-GFP/+ (Atoh1-Gli2 CKO; Atoh1-GFP) mouse. EGL is indicated by the yellow doted line and black arrowheads indicate ATOH1-GFP+/ Cre + cells. Scale bars represent $100 \mu \mathrm{m}$ (a and b) and $10 \mu \mathrm{m}$ (d). (JPG $864 \mathrm{~kb}$ )

Additional file 4: Figure S4. Nestin-Expressing Progenitors (NEPS) differentiate into granule neurons in response to loss of Gli2 in the hemispheres. (a and c) H\&E staining of hemispheric sagittal sections of P30 Nes-FlpoER/t; R26 FSF-TDTom/+ (Nes-TDTom, a) and Atoh1-Cre/t; Gli2 ${ }^{\text {lox/lox }}$ Nes-FlpoER/t; R26 FSF-TDTom/+ (Atoh1-Gli2 CKO; Nes-TDTom, c) mice injected ' with Tm at PO. (b and d) FIHC detection of the indicated proteins and dapi on hemispheric sagittal cerebellar sections at P30. High power images are shown of the areas indicated by yellow rectangles in (a and c). IGL is indicated by the yellow doted line. Scale bars represent $1 \mathrm{~mm}$ (a and c) and $100 \mu \mathrm{m}$ (b and d). (JPG $1479 \mathrm{~kb}$ )

Additional file 5: Video S1. P8 WT cerebellum shows no obvious movement of NEPs towards the EGL. Detection of native CFP fluorescence on sagittal slices of the vermis (lobule 2/3) of P8 Nes-CFP/+ mice showing displacement of CFP+ cells. Image stacks were acquired every 5 min for $4 \mathrm{~h}$. (MOV $3481 \mathrm{~kb}$ )

Additional file 6: Video S2. PCL NEPs migrate toward the EGL in Atoh1-Gli2 CKO CB at P8. Detection of native CFP fluorescence on sagittal slices of the vermis (lobule 2/3) of P8 Atoh1-Cre/t; Gli2 floxfflox; Nes-CFP/+ (Atoh1-Gli2 CKO; Nes-CFP) mice showing displacement of CFP+ cells. Image stacks were acquired every 5? min for 4?h. (MOV $1740 \mathrm{~kb}$ )

Additional file 7: Video S3. A subset of NEP-derived cells migrate from the EGL towards the IGL in Atoh1-Gli2 CKO CB at P8. Detection of native CFP fluorescence on sagittal slices of the vermis (lobule 1/2) of P8 Atoh 1-Cre/+; Gli2 flox/flox; Nes-CFP/+ (Atoh1-Gli2 CKO; Nes-CFP) mice showing displacement of CFP+ cells. Image stacks were acquired every 5? min for 4?h. (MOV $6450 \mathrm{~kb}$ )

Additional file 8: Figure S5. Inactivation of Gli2 in both Nestin and Atoh1 expressing cells inhibits the recovery of the CB. (a, c, e and g) H\&E staining of sagittal sections of the cerebellar vermis of P8 $\mathrm{Gli}^{\text {flox fflox }}$ (Control, a),

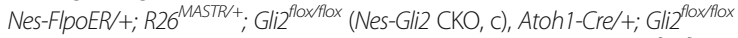
(Atoh1-Gli2 CKO, e), and Atoh1-Cre/t; Nes-FlpoER/t; R26 ${ }^{\text {MASTR/t }}$; Gli2 foxfllox (Atoh1Nes-Gli2 CKO, g) mice injected with Tm at PO. Note that inactivation of Gli2 only in Nestin-expressing cells has no major effect at P8. However, inactivation of Gli2 in Nestin-expressing cells inhibits the compensation mechanism (g compared to e). (b, d, f and h) Close-up (as shown by yellow squares in a, c, e and $g$ ) of

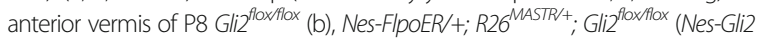
CKO, d), Atoh1-Cre/t; Gli2 floxflox (Atoh1-Gli2 CKO, f), and Atoh1-Cre/+; Nes-FlpoER +; R26 MASTR+ ; Gli2 $2^{\text {floxflox }}$ (Atoh1-Nes-Gli2 CKO, h) cerebella stained with the indicated proteins and dapi. White arrowhead and white asterisk indicate the loss of EGL and IGL respectively in the Atoh 1-Nes-Gli2 CKO. Scale bars represent 1 $\mathrm{mm}(\mathrm{a}, \mathrm{c}, \mathrm{e}$ and $\mathrm{g})$ and $100 \mu \mathrm{m}$ (b, d, f and h). (JPG $2032 \mathrm{~kb})$ 


\section{Abbreviations}

A: Activator; CB: Cerebellum; Ci: Cubitus interruptus; CKO: Conditional knockout; Dhh: Desert hedgehog; EGL: External Granule Layer; GCP: Granule Cell Precursor; GFP: Green Fluorescent Protein; GIFM: Genetic Inducible Fate Mapping; het: Heterozygous; HH: Hedgehog; IGL: Internal granule cell layer; IHC: immunohistochemistry; Ihh: Indian hedgehog; ISH: In situ hybridization; MASTR: Mosaic mutant analysis with spatial and temporal control of recombination; ML: Molecular layer; NEP: Nestin-expressing progenitor; P: Postnatal day; PC: Purkinje cell; PCL: Purkinje cell layer; PTCH1: Patched1; R: Repressor; SHH: Sonic Hedgehog; SMO: Smoothened; TDTom: Tandem Dimeric derivative of DsRed; Tm: Tamoxifen; TUNEL: Terminal deoxynucleotidyl transferase dUTP nick end labeling; VZ: ventricular zone; WT: Wild type

\section{Acknowledgments}

We thank the past and present members of the laboratory for helpful discussions during the course of our study.

\section{Funding}

This work was supported by grants from the Brain Tumor Center at MSKCC and from the Philippe Foundation (to A.W), and from the NIH (R37 MH085726 and R01 NS092096 to A.L.J and F32 NS086163 to A.K.L.) and a National Cancer Institute Cancer Center Support Grant (P30 CA008748-48).

\section{Availability of data and materials}

All mouse lines are available from the Joyner lab or Jackson laboratories. All data generated or analyzed for this study are included in this published article.

\section{Authors' contributions}

AW and $A L J$ conceived the project; $A W, A K L$ and $A L J$ designed the research: AW, MM, AKL and DNS performed the experiments; AW, MM, AKL and ALJ analyzed the data and all authors discussed the data; AW and ALJ wrote the manuscript with contributions from all authors. All authors read and approved the final manuscript.

\section{Ethics approval and consent to participate}

All animal procedures were performed according to a protocol (07-01-001) approved by the Memorial Sloan Kettering Cancer Center's Institutional Animal Care and Use Committee.

\section{Competing interests}

The authors declare that they have no competing interests.

\section{Publisher's Note}

Springer Nature remains neutral with regard to jurisdictional claims in published maps and institutional affiliations.

\section{Received: 19 July 2018 Accepted: 17 January 2019}

\section{Published online: 14 February 2019}

\section{References}

1. Azevedo FA, Carvalho LR, Grinberg LT, Farfel JM, Ferretti RE, Leite RE, et al. Equal numbers of neuronal and nonneuronal cells make the human brain an isometrically scaled-up primate brain. J Comp Neurol. 2009;513(5):532-41.

2. Herculano-Houzel S, Mota B, Lent R. Cellular scaling rules for rodent brains. Proc Natl Acad Sci U S A. 2006;103(32):12138-43.

3. Steinlin M. The cerebellum in cognitive processes: supporting studies in children. Cerebellum. 2007;6(3):237-41.

4. Tomlinson SP, Davis NJ, Bracewell RM. Brain stimulation studies of nonmotor cerebellar function: a systematic review. Neurosci Biobehav Rev. 2013;37(5):766-89.

5. Ito M. Control of mental activities by internal models in the cerebellum. Nat Rev Neurosci. 2008;9(4):304-13.

6. Buckner RL. The cerebellum and cognitive function: 25 years of insight from anatomy and neuroimaging. Neuron. 2013;80(3):807-15.

7. Strick PL, Dum RP, Fiez JA. Cerebellum and nonmotor function. Annu Rev Neurosci. 2009;32:413-34.

8. Altman J, Bayer SA. Development of the cerebellar system in relation to its evolution, structure, and functions. Boca Raton: CRC Press; 1997.
9. Rakic P, Sidman RL. Histogenesis of cortical layers in human cerebellum, particularly the lamina dissecans. J Comp Neurol. 1970;139(4):473-500.

10. Dobbing J, Sands J. Quantitative growth and development of human brain. Arch Dis Child. 1973:48(10):757-67.

11. Wang SS, Kloth AD, Badura A. The cerebellum, sensitive periods, and autism Neuron. 2014:83(3):518-32

12. Hoshino M, Nakamura S, Mori K, Kawauchi T, Terao M, Nishimura $\mathrm{Y}$, et al. Ptf1a, a bHLH transcriptional gene, defines GABAergic neuronal fates in cerebellum. Neuron. 2005;47(2):201-13.

13. Fleming JT, He W, Hao C, Ketova T, Pan FC, Wright CC, et al. The Purkinje neuron acts as a central regulator of spatially and functionally distinct cerebellar precursors. Dev Cell. 2013;27(3):278-92.

14. Parmigiani E, Leto K, Rolando C, Figueres-Onate M, Lopez-Mascaraque L, Buffo A, et al. Heterogeneity and Bipotency of Astroglial-like cerebellar progenitors along the interneuron and glial lineages. J Neurosci. 2015:35(19):7388-402.

15. Kawaguchi Y, Cooper B, Gannon M, Ray M, MacDonald RJ, Wright CV. The role of the transcriptional regulator Ptf1a in converting intestinal to pancreatic progenitors. Nat Genet. 2002;32(1):128-34

16. Wingate RJ, Hatten ME. The role of the rhombic lip in avian cerebellum development. Development. 1999;126(20):4395-404.

17. Machold R, Fishell G. Math1 is expressed in temporally discrete pools of cerebellar rhombic-lip neural progenitors. Neuron. 2005;48(1):17-24.

18. Wang WY, Rose MF, Zoghbi HY. Math1 expression redefines the rhombic lip derivatives and reveals novel lineages within the brainstem and cerebellum. Neuron. 2005:48(1):31-43.

19. Sillitoe RV, Joyner AL. Morphology, molecular codes, and circuitry produce the three-dimensional complexity of the cerebellum. Annu Rev Cell Dev Biol. 2007:23:549-77.

20. Corrales JD, Blaess S, Mahoney EM, Joyner AL. The level of sonic hedgehog signaling regulates the complexity of cerebellar foliation. Development. 2006;133(9):1811-21.

21. Lewis PM, Gritli-Linde A, Smeyne R, Kottmann A, McMahon AP. Sonic hedgehog signaling is required for expansion of granule neuron precursors and patterning of the mouse cerebellum. Dev Biol. 2004;270(2):393-410.

22. Bohn MC, Lauder JM. The effects of neonatal hydrocortisone on rat cerebellar development: an autoradiographic and light microscopic study. Dev Neurosci. 1978;1:250-66.

23. Heine VM, Rowitch $\mathrm{DH}$. Hedgehog signaling has a protective effect in glucocorticoid-induced mouse neonatal brain injury through an 11 betaHSD2-dependent mechanism. J Clin Invest. 2009;119(2):267-77.

24. Altman J, Anderson WJ, Wright KA. Early effects of X-irradiation of the cerebellum in infant rats: decimation and reconstitution of the external granular layer. Exp Neurol. 1969;24:196-216.

25. Wojcinski A, Lawton AK, Bayin NS, Lao Z, Stephen DN, Joyner AL. Cerebellar granule cell replenishment postinjury by adaptive reprogramming of nestin (+) progenitors. Nat Neurosci. 2017;20(10):1361-70.

26. Andreotti JP, Prazeres P, Magno LAV, Romano-Silva MA, Mintz A, Birbrair A. Neurogenesis in the postnatal cerebellum after injury. Int J Dev Neurosci. 2018:67:33-6.

27. Jaeger BN, Jessberger $\mathrm{S}$. Unexpected help to repair the cerebellum. Nat Neurosci. 2017:20(10):1319-21.

28. Ingham PW, McMahon AP. Hedgehog signaling in animal development: paradigms and principles. Genes Dev. 2001:15(23):3059-87.

29. Varjosalo M, Taipale J. Hedgehog: functions and mechanisms. Genes Dev. 2008;22(18):2454-72.

30. Allen MC. Neurodevelopmental outcomes of preterm infants. Curr Opin Neurol. 2008;21(2):123-8.

31. Goetz SC, Anderson KV. The primary cilium: a signalling Centre during vertebrate development. Nat Rev Genet. 2010;11(5):331-44.

32. Fuccillo M, Joyner AL, Fishell G. Morphogen to mitogen: the multiple roles of hedgehog signalling in vertebrate neural development. Nat Rev Neurosci. 2006:7(10):772-83.

33. Bai CB, Auerbach W, Lee JS, Stephen D, Joyner AL. Gli2, but not Gli1, is required for initial Shh signaling and ectopic activation of the Shh pathway. Development. 2002;129(20):4753-61.

34. Bai CB, Stephen D, Joyner AL. All mouse ventral spinal cord patterning by hedgehog is Gli dependent and involves an activator function of Gli3. Dev Cell. 2004:6(1):103-15.

35. Lee Y, Miller HL, Russell HR, Boyd K, Curran T, McKinnon PJ. Patched2 modulates tumorigenesis in patched1 heterozygous mice. Cancer Res. 2006 66(14):6964-71. 
36. Blaess S, Stephen D, Joyner AL. Gli3 coordinates three-dimensional patterning and growth of the tectum and cerebellum by integrating Shh and Fgf8 signaling. Development. 2008;135(12):2093-103.

37. Yang ZJ, Ellis T, Markant SL, Read TA, Kessler JD, Bourboulas M, et al. Medulloblastoma can be initiated by deletion of patched in lineagerestricted progenitors or stem cells. Cancer Cell. 2008;14(2):135-45.

38. Corrales JD, Rocco GL, Blaess S, Guo Q, Joyner AL. Spatial pattern of sonic hedgehog signaling through Gli genes during cerebellum development. Development. 2004;131(22):5581-90.

39. De Luca A, Parmigiani E, Tosatto G, Martire S, Hoshino M, Buffo A, et al. Exogenous sonic hedgehog modulates the pool of GABAergic interneurons during cerebellar development. Cerebellum. 2015;14(2):72-85.

40. Lao Z, Raju GP, Bai CB, Joyner AL. MASTR: a technique for mosaic mutant analysis with spatial and temporal control of recombination using conditional floxed alleles in mice. Cell Rep. 2012;2(2):386-96.

41. Matei V, Pauley S, Kaing S, Rowitch D, Beisel KW, Morris K, et al. Smaller inner ear sensory epithelia in Neurog 1 null mice are related to earlier hair cell cycle exit. Dev Dyn. 2005;234(3):633-50.

42. Lumpkin EA, Collisson T, Parab P, Omer-Abdalla A, Haeberle H, Chen P, et al. Math1-driven GFP expression in the developing nervous system of transgenic mice. Gene Expr Patterns. 2003;3(4):389-95.

43. Mignone JL, Kukekov V, Chiang AS, Steindler D, Enikolopov G. Neural stem and progenitor cells in nestin-GFP transgenic mice. J Comp Neurol. 2004; 469(3):311-24

44. Schuller U, Heine VM, Mao J, Kho AT, Dillon AK, Han YG, et al. Acquisition of granule neuron precursor identity is a critical determinant of progenitor cell competence to form Shh-induced medulloblastoma. Cancer Cell. 2008;14(2): 123-34.

45. Orvis GD, Hartzell AL, Smith JB, Barraza LH, Wilson SL, Szulc KU, et al. The engrailed homeobox genes are required in multiple cell lineages to coordinate sequential formation of fissures and growth of the cerebellum. Dev Biol. 2012;367(1):25-39.

46. Wijayatunge R, Liu F, Shpargel KB, Wayne NJ, Chan U, Boua JV, et al. The histone demethylase $\mathrm{Kdm} 6 \mathrm{~b}$ regulates a mature gene expression program in differentiating cerebellar granule neurons. Mol Cell Neurosci. 2018;87:4-17.

47. Nakamura T, Ueyama T, Ninoyu Y, Sakaguchi H, Choijookhuu N, Hishikawa Y, et al. Novel role of Rac-Mid1 signaling in medial cerebellar development Development. 2017;144(10):1863-75.

48. Pan N, Jahan I, Lee JE, Fritzsch B. Defects in the cerebella of conditional Neurod1 null mice correlate with effective $\mathrm{Tg}$ (Atoh1-cre) recombination and granule cell requirements for Neurod 1 for differentiation. Cell Tissue Res. 2009:337(3):407-28.

49. Constantin L, Wainwright BJ. MicroRNAs promote granule cell expansion in the cerebellum through Gli2. Cerebellum. 2015;14(6):688-98.

50. Lorenz A, Deutschmann M, Ahlfeld J, Prix C, Koch A, Smits R, et al. Severe alterations of cerebellar cortical development after constitutive activation of Wht signaling in granule neuron precursors. Mol Cell Biol. 2011;31(16):3326-38.

51. Julian E, Hallahan AR, Wainwright BJ. RBP-J is not required for granule neuron progenitor development and medulloblastoma initiated by hedgehog pathway activation in the external germinal layer. Neural Dev. 2010;5:27.

52. Schuller U, Zhao Q, Godinho SA, Heine VM, Medema RH, Pellman D, et al. Forkhead transcription factor FoxM1 regulates mitotic entry and prevents spindle defects in cerebellar granule neuron precursors. Mol Cell Biol. 2007; 27(23):8259-70.

53. Klein RS, Rubin JB, Gibson HD, DeHaan EN, Alvarez-Hernandez X, Segal RA, et al. SDF-1 alpha induces chemotaxis and enhances sonic hedgehoginduced proliferation of cerebellar granule cells. Development. 2001;128(11): 1971-81.

54. Inaguma S, Riku M, Ito H, Tsunoda T, Ikeda H, Kasai K. GLI1 orchestrates CXCR4/CXCR7 signaling to enhance migration and metastasis of breast cancer cells. Oncotarget. 2015;6(32):33648-57.

55. Tan IL, Wojcinski A, Rallapalli H, Lao Z, Sanghrajka RM, Stephen D, et al. Lateral cerebellum is preferentially sensitive to high sonic hedgehog signaling and medulloblastoma formation. Proc Natl Acad Sci U S A. 2018; 115(13):3392-7.

\section{Ready to submit your research? Choose BMC and benefit from:}

- fast, convenient online submission

- thorough peer review by experienced researchers in your field

- rapid publication on acceptance

- support for research data, including large and complex data types

- gold Open Access which fosters wider collaboration and increased citations

- maximum visibility for your research: over $100 \mathrm{M}$ website views per year

At BMC, research is always in progress.

Learn more biomedcentral.com/submissions 